\title{
Atenção domiciliar à saúde: revisão dos custos associados no Brasil e nos Estados Unidos
}

\author{
Adalto Alfredo PONTES ${ }^{(1)}$ \\ Lúcia Dias da Silva GUERRA ${ }^{(1)}$
}

${ }^{(1)}$ Hospital das Clínicas, Faculdade de Medicina, Universidade de São Paulo - HCFMUSP, São Paulo, SP, Brasil.

Recebido: 28 jan 2019 Aceito: 10 fev 2019

Autor de correspondência: adaltopontes@hotmail.com

Conflito de interesses: Os autores declaram não haver nenhum interesse profissional ou pessoal que possa gerar conflito de interesses em relação a este manuscrito.

\section{Resumo}

O cuidado domiciliar à saúde é prática milenar que remota a existência da família como unidade estruturante da sociedade, e o domicílio como espaço de convivência do núcleo familiar. Já descrito em textos históricos do Egito e Grécia Antiga, o cuidado em saúde no ambiente domiciliar desta época tem pouco em comum com o que na atualidade denominamos Atenção Domiciliar à Saúde (ADS). Em tais épocas, o cuidar em saúde pode ser compreendido como extensão do papel social da unidade familiar, visto a inexistência de profissionais e serviços de saúde da forma que conhecemos hoje. Tal prática só será questionada, ou posta à prova, com o advento do hospital como estrutura moderna centralizadora e monopolizadora dos cuidados em saúde, amplamente impulsionada pelo desenvolvimento da Medicina Científica, a partir de meados do século XIX. Se o sucesso da Medicina Científica pode ser apontado como responsável pela perda do status dos cuidados domiciliares, atualmente os excessos da medicina baseada nas ciências biomédicas, estruturante das instituições hospitalares, parece ser o ponto de inflexão que tem levado pacientes, famílias e profissionais a questionar a supremacia hospitalar nos cuidados em saúde. No Brasil, tem-se observado nos últimos 20 anos o aumento progressivo do número de serviços de ADS. Tal movimento parece se justificar por três razões principais. A primeira delas, como descrito acima, diz respeito ao questionamento levantado pela sociedade quanto aos excessos, malefícios e limitações da medicina hospitalar para os cuidados de pacientes crônicos, ou em reabilitação de longo prazo. Um exemplo que ilustra esse fato são as infecções nosocomiais por patógenos multirresistentes adquiridas em internações hospitalares. Uma segunda razão diz respeito ao desenvolvimento de tecnologias substitutivas àquelas de uso exclusivo às unidades hospitalares, o que permite a prestação de cuidados de níveis mais complexo em outros contextos, como o domiciliar. Pode-se citar a facilidade no aporte de terapia de suporte ventilatório e oxigenioterapia como exemplos. O terceiro, e certamente mais importante, diz respeito aos custos associados à assistência hospitalar, reconhecidos como problemas centrais em qualquer sistema de saúde. Apesar do histórico extenso da ADS e sua potencial capacidade de contribuir para melhorar a eficiência dos sistemas de saúde, a mesma ainda não está estruturada plenamente para este fim. Por ser extremamente abrangente e possuir uma diversidade de configurações possíveis, a ADS não possui um conceito único que integre as diferentes dimensões em que está envolvida. A ADS é definida pelo Ministério da Saúde brasileiro, como uma modalidade de atenção à saúde, constituída por um conjunto de ações de promoção à saúde, prevenção, tratamento e reabilitação, prestada em domicílio, de forma integrada à Rede de Atenção à Saúde. No âmbito do SUS, a ADS tem se organizado a partir da rede de atenção primária à saúde, tendo como principal programa estruturante o Melhor em casa, criado em 2011. Objetivo: O objetivo deste estudo é comparar os custos associados à ADS no Brasil e nos Estados 
Unidos. Método: O estudo proposto será realizado por meio de uma revisão de literatura integrativa, utilizando a bases de dados PubMed e LILACS. Para guiar esta revisão foi elaborada a seguinte pergunta de pesquisa: "Quais são os custos associados à ADS no Brasil e nos Estado Unidos, e de que modo estes se relacionam com os modelos assistenciais e sistemas nacionais de saúde destes países?". Selecionou-se os seguintes Descritores de Ciências da Saúde (DeCS): Serviços de Assistência Domiciliar, Serviços Hospitalares de Assistência Domiciliar, Agências de Assistência Domiciliar, Visita Domiciliar, Custos e Análise de Custo, Custos de Cuidados de Saúde, Gastos em Saúde, Organização e Administração. A sintaxe utilizada para a busca nas bases de dados Medline e Lilacs, foram as seguintes: no MEDLINE ((()((Home Care Services[MeSH Terms]) OR Home Care Services, Hospital-Based[MeSH Terms]) OR Home Care Agencies[MeSH Terms]) AND House Calls[MeSH Terms]) OR (Costs and Cost Analysis[MeSH Terms])) OR Health Care Costs[MeSH Terms]) OR Health Expenditures[MeSH Terms]) AND (Organization and Administration[MeSH Terms]), e na LILACS (tw:(Serviços de Assistência Domiciliar)) OR (tw:(Serviços Hospitalares de Assistência Domiciliar)) OR (tw:(Agências de Assistência Domiciliar)) OR (tw:(Visita Domiciliar)) AND (tw:(Custos e Análise de Custo)) OR (tw:(Custos de Cuidados de Saúde)) OR (tw:(Gastos em Saúde)) OR (tw:(Organização e Administração)). Resultados Esperados: pretende-se caracterizar a ADS nos países em estudo; descrever os principais itens de custo relacionados à ADS nos países em estudo; estudar as principais características dos sistemas de saúde dos países em estudo, considerando os modelos técnico-assistenciais presentes na ADS; e relacionar os custos associados à ADS com os modelos técnico-assistenciais e de sistemas de saúde dos países em estudo. Considerações finais: Apesar dos avanços da ADS nas últimas décadas, esta modalidade de assistência à saúde ainda é pouco estruturada e estudada. Em análise preliminar dos resultados da pesquisa nas bases de dados, observa-se que grande parte da literatura disponível se trata de relatos de experiência ou publicações amparadas no empirismo do autor. Tal fato pode indicar a necessidade de maior investimento neste campo, visto seu potencial como reorganizador da atenção à saúde de pacientes com condições crônicas ou em contexto de terminalidade de vida.

Descritores: Serviços de Assistência Domiciliar; Custos de Cuidado em Saúde; Gastos em Saúde; Modelos de Assistência à Saúde; Sistemas de Saúde. 